\title{
Correction to: Risk Factors for Death Among Hospitalized Patients Aged 21-64 Years Diagnosed with COVID-19—New York City, March 13-April 9, 2020
}

\author{
Dena Bushman ${ }^{1,2}\left(\right.$ D Alexander Davidson ${ }^{1} \cdot$ Preeti Pathela $^{1} \cdot$ Sharon K. Greene ${ }^{1} \cdot$ Don Weiss $^{1} \cdot$ Vasudha Reddy $^{1} \cdot$ New \\ York City Fatal Case-Control Study Team ${ }^{1}$. Julia Latash ${ }^{1}$
}

Published online: 8 September 2021

(c) W. Montague Cobb-NMA Health Institute 2021

\section{Correction to: Journal of Racial and Ethnic Health Disparities https://doi.org/10.1007/s40615-021-01098-1}

The journal published errors in Table 1, 2, and 3 which have now been corrected. In Table 1, Staten Island is now correctly shown as one of the five boroughs of New York City. In Table 2, hospital course including diagnosis of pneumonia and acute respiratory distress syndrome, use and type of respiratory support, dialysis initiation, intensive care unit admission, and median length of stay (in days) are now shown correctly. In Table 3, underlying medical conditions are now correctly categorized.

The original article has been corrected.

Publisher's Note Springer Nature remains neutral with regard to jurisdictional claims in published maps and institutional affiliations.

The original article can be found online at https://doi.org/10.1007/ s40615-021-01098-1.

Dena Bushman pgz3@cdc.gov

1 New York City Department of Health and Mental Hygiene, Queens, NY, USA

2 Epidemic Intelligence Service, Centers for Disease Control and Prevention, Atlanta, GA, USA 